\title{
A techno-economic comparison of Fischer-Tropsch and fast pyrolysis as ways of utilizing sugar cane bagasse in transportation fuels production.
}

DOI:

10.1016/j.cherd.2017.01.001

\section{Document Version}

Accepted author manuscript

Link to publication record in Manchester Research Explorer

Citation for published version (APA):

Michailos, S., Parker, D., \& Webb, C. (2017). A techno-economic comparison of Fischer-Tropsch and fast pyrolysis as ways of utilizing sugar cane bagasse in transportation fuels production. Chemical Engineering Research and Design, 118, 206-214. https://doi.org/10.1016/j.cherd.2017.01.001

Published in:

Chemical Engineering Research and Design

\section{Citing this paper}

Please note that where the full-text provided on Manchester Research Explorer is the Author Accepted Manuscript or Proof version this may differ from the final Published version. If citing, it is advised that you check and use the publisher's definitive version.

\section{General rights}

Copyright and moral rights for the publications made accessible in the Research Explorer are retained by the authors and/or other copyright owners and it is a condition of accessing publications that users recognise and abide by the legal requirements associated with these rights.

\section{Takedown policy}

If you believe that this document breaches copyright please refer to the University of Manchester's Takedown Procedures [http://man.ac.uk/04Y6Bo] or contact uml.scholarlycommunications@manchester.ac.uk providing relevant details, so we can investigate your claim.

\section{OPEN ACCESS}




\section{A techno-economic comparison of Fischer-Tropsch and fast}

\section{2 pyrolysis as ways of utilizing sugar cane bagasse in}

\section{3 transportation fuels production.}

4 Stavros Michailos a, David Parker b , Colin Webb a,

5 a School of Chemical Engineering and Analytical Science, The University of Manchester,

6 Oxford Road, Manchester, M13 9PL, UK

$7 \quad{ }^{\mathrm{b}}$ School of Biosciences, University of Exeter, Stocker Road, Exeter, EX4 4QD, UK

8

9

*Corresponding Author

\section{E-mail address: colin.webb@manchester.ac.uk (C. Webb)}

Keywords: Techno-economic analysis, 2G biofuels, Process Simulation, Fischer-Tropsch (FT) synthesis, Fast pyrolysis

Abstract: Due to limited biomass availability, the establishment of optimal route biofuel value chains (one conversion route for each feedstock) is a key prerequisite for a feasible bioenergy sector. This way, biorefineries can take advantage of the economies of scale and increase their economic potential. Therefore, techno-economic comparison between similar conversion processes for the utilisation of individual feedstocks is essential. To this effect, the present study focuses on the feasibility of two biomass to liquids (BtL) thermochemical conversion routes for the production of hydrocarbon fuels. Aspen plus software was 
employed to investigate a gasification followed by Fischer-Tropsch synthesis route (G-FT)

and fast pyrolysis followed by hydroprocessing (FP-H) by developing process flowsheets and solving the associated mass, and energy balances. Based on the simulations, thermodynamic (energy/exergy analysis) and economic (financial and risk analysis) evaluations were carried out. Sensitivity analyses have been performed in order to define the key parameters of each conversion route. Sugar cane bagasse, the waste solid residue of the sugar cane milling process, was considered as feedstock at a flowrate of $100 \mathrm{t} / \mathrm{h}$. Based on the outcomes of the evaluations, the two alternatives were compared and it was concluded that, both energetically and financially, G-FT synthesis is the more efficient option.

\section{Introduction}

During the last few decades the critical issues of energy security, petrol price increase and rising awareness of global warming, have drawn society's attention to the prospects of a bioenergy sector. Various policies have been implemented throughout these years in order to give a significant boost to this direction and governments have applied massive investments in exploration and expansion of biomass conversion routes. The constant increase in carbon dioxide emissions coupled with the restricted supply of fossil fuels, has brought forth considerations relating to the sustainability of our world in terms of attaining a less polluted environment [Murphy and Kendall, 2015]. In view of this and the related, inevitable, depletion of fossil reserves, the biorefinery concept has recently emerged. Biomass is the sole renewable energy source that can produce liquid fuels with properties similar to fossil fuels. Biomass as an energy feedstock offers numerous benefits such as: 1) Improvement of energy security and accessibility through the replacement of imported fossil fuels, 2) decreased oil dependency, 3) expansion of the current energy market, 4) 
employment opportunities, 5) growth of the agricultural sector and 6) Decreased emissions of sulphur and nitrogen oxides compared to fossil fuels [Chauhan et al., 2011].

The shift from conventional energy sources to biomass to produce value added products, including biofuels, has generated much discussion during recent years. Subsequent technologies manufacturing first generation $(1 \mathrm{G})$ biofuels are at present well-established but interestedly, little interest has been shown to-date in the exploitation of the residues from such bio-refineries. Sugarcane is presently the most cost effective feedstock for biofuel (ethanol) production and could be even more cost effective if the waste bagasse, a lignocellulosic material, could also be converted to biofuels. Back in 2012 the global production of sugarcane was 670 million tonnes [Luo et al., 2009] which left as residue approximately 336 million tonnes of bagasse, resulting in a disposal issue. Thus it is sensible to consider bagasse as a potential feedstock for a sustainable biofuel sector. Its exploitation in this way would provide a significant solution to overcome waste problems. Moreover, as a waste material, it will be considerably less expensive than other biomass material such as wood [Kiatkittipong et al., 2009]. Another advantage is that there is no competition with the accessibility and usage of food and land [Botha and Von blottnitz, 2006]. Essentially, it precludes the tightness of food supply and averts the conflict with the cultivation of farmland [Chandel et al., 2012]. Similarly to various energy crops, it manages neutral carbon footprint and its composition (high holocellulose content) makes it appropriate for a number of conversion procedures.

A large variety of technologies exist for exploiting biomass so as to produce a wide range of fuels. In this study, the alternative conversion pathways were chosen based on three criteria. One, the process under investigation should have the potential to be commercially available 

in the next 5-10 years and preferably presently has achieved substantial technology development. Hence, since G-FT and FP-H have already been used for liquid fuels production from coal, are both suitable candidates. Two, the size of the production plant should be practical with the current agricultural status. According to this, sugar cane bagasse was selected as a raw material feedstock for the examined procedures due to its relatively high availability in that timeframe [Anex et al., 2010]. Three, the compatibility of the final products with the current gasoline and/or diesel infrastructure is essential, and thereby technologies like G-FT and FP-H, which produce diesel and gasoline ranged fuels, are of high interest.

In recent years, several technoeconomic analysis studies have been carried out for FT and FP fuels production. Based in these, estimated production costs for such fuels have ranged from $11 £ / G J$ to $18 £ / G J$ (converted from reported currencies and scaled to 2014). Hamelinck et al. [2004] explored the technical and economic feasibility of various process configurations for FT fuels production from biomass. They concluded that a production cost of $14.7 £ / G \mathrm{~J}$ can be achieved under certain conditions (e.g. feedstock cost, plant scale, technical configurations). The Pacific Northwest National Laboratory [Zhu et al., 2011] compared the performance of two gasification - FT systems, based on different types of gasifiers namely, indirect and direct heat. The latter technology can produce FT fuels at a cost of $16.7 £ / G J$ while the former at 14.5. The PNNL has also conducted a study on the feasibility of producing fuels by fast pyrolysis followed by hydroprocessing [Jones et al., 2013]. The estimated minimum fuel selling price (MFSP) was $16.73 £ / G J$. The National Renewable Energy Laboratory (NREL) [Swanson et al., 2010] explored the feasibility of two scenarios based on biomass gasification. The selected scenarios are high-temperature (HT) gasification and low- 
temperature (LT) gasification, each followed by Fischer-Tropsch synthesis and hydroprocessing. The production cost for the HT was $15 £ / G J$ whereas for the LT scenario 15.8 $£ / G J$. Also, the NREL developed a techno-economic model for assessing the conversion of biomass to valuable fuel products via fast pyrolysis and bio-oil upgrading [Wright et al., 2010]. The fuels are produced from corn stover at a product value of $15.5 £ / G J$. In the Energy Research Centre of the Netherlands (ECN), Boerrigter [2006] conducted an economic analysis, coupled with a brief thermodynamic assessment, on a FT fuels production process. The efficiency of the procedure was found to be $55 \%$ and the estimated production cost of the FT fuels was 11.8 £/GJ. Ng and Sadhukhan [2011] investigated the potential of gasifying pyrolysis oil and then upgrading to transportation fuels. This approach, driven by logistic considerations, yielded a production cost of FT liquids of $17.9 £ / G J$. Finally, an analysis carried out at Iowa State University [Wright et al., 2011] determined the MFSP of gasoline and diesel fuel produced via fast pyrolysis and hydroprocessing to be $15.3 £ / G J$. These are interesting findings but, to the best of our knowledge, no direct comparisons between alternative BtL processes have been attempted. Thus, the present study is focused on making such comparisons by integrating exhaustive process simulations along with thorough energetic and economic calculations to evaluate the techno-economic feasibility, and eventually suggest the best alternative.

A comparative feasibility analysis is carried out in this study regarding the exploitation of bagasse in order to strengthen the biorefinery concept, particularly for those first generation biorefineries based on cane sugar. Due to limited biomass availability and the resultant necessity of developing biofuel value chains, this research focuses on assessment of two BtL processes for bagasse utilisation namely, gasification coupled with Fischer-Tropsch 
synthesis and a fast pyrolysis-hydroprocessing route. The study compares, in terms of technological and economic feasibility two processes that give, as final products, fuels that can be directly utilised within the present technological infrastructure.

\section{Process modelling}

The inlet mass flow rate for all the cases was set equal to $100 \mathrm{t} / \mathrm{h}$ [Cardona et al., 2010]. User defined non-conventional solids were determined to symbolize bagasse and ash. Aimed at those modules two Aspen models were allocated: one for the density (DCOALIGT) and the second one enthalpy (HCOALGEN) that necessitates awareness of proximate analysis and ultimate analysis of the bagasse (see Table 1) [Cao et al., 2013]. The physical properties of the conventional components have been estimated by using the Redlich-Kwong-Soave cubic equation of state with Boston-Mathias alpha function (RKS-BM). This method is suitable for gas-processing, refinery and petrochemical applications such as gas plants, crude towers and ethylene plants. RKS-BM is normally utilised for nonpolar or mildly polar mixtures. Using the RKS-BM model, rational and reliable outcomes can be anticipated at all temperatures and pressures. The SOLIDS property option was employed for the biomass crushing and drying units as it is recommended for solids processing unit operations.

For both process pretreatment of bagasse is essential before it enters the gasification or pyrolysis unit. Pretreatment section consists of bagasse crushing to small particles and drying. A standard Aspen plus block for a crusher was employed to simulate a gyratory crusher which chops bagasse to a final particle size equal to $2 \mathrm{~mm}$ [Luo et al., 2011]. A gyratory crusher was selected due to its low power requirement, robust construction and low operating costs. After this, bagasse enters a dryer in order to reduce its moisture content 
to $10 \%$. For this purpose a fluidised bed dryer was used since the high rate of heat and mass transfer accomplished guarantees much faster and more homogeneous drying than attained by using other techniques such as oven and vacuum drying [Luo et al., 2011]. The high initial moisture content of bagasse makes it necessary to employ a dryer so as to reduce heat losses in the gasification/pyrolysis unit. The fractional conversion of bagasse to water was estimated by embedding a FORTRAN statement into the main model. The energy required for the drying process is provided by the flue gas exiting the power generation unit. After the dryer a common separator block was used to remove the moisture.

(Tab1 here)

Conversion of biomass derived syngas conversion to liquid fuels can be achieved via FT synthesis. FT is a common and well known technology for producing liquid fuels from solids (coal, biomass) or gases (natural gas). The FT process is capable of providing fuels that can be used directly as alternatives to petrol gasoline and diesel without any modifications to the current commercial combustion engines. The steps within the G-FT route can be classified as follows: 1) gasifier island, 2) syngas quenching and cleaning, 4) FT synthesis reactor, 5) product recovery and separation and 6) heat and power generation system. A steam fluidised bed reactor was considered operating at atmospheric pressure, temperature of $1150 \mathrm{~K}$ and steam to biomass ratio of 1.25 . The equilibrium model approach was adopted and thereby the gasifier was modelled with an RGIBBS reactor (by identifying the possible products) in Aspen Plus. At these conditions, $\mathrm{H}_{2}: \mathrm{CO}$ ratio achieves a value of 2.05 . 
Afterwards, a catalytic tar reformer converts tar (simulated as toluene) and methane into syngas $\left(\mathrm{CO}\right.$ and $\mathrm{H}_{2}$ ). Subsequently the acid gases $\mathrm{H}_{2} \mathrm{~S}$ and $\mathrm{CO}_{2}$ are removed by using a solution of monoethanolamine (MEA) in an absorber. The entrainer is recovered in a stripper and recycled to the absorber. The core of this pathway is the FT reactor where various catalytic chemical reactions take place, which in general can be expressed as follows [Hamelinck et al., 2004]:

$$
n \mathrm{CO}+2 n \mathrm{H}_{2} \rightarrow-\left(\mathrm{CH}_{2}\right) n-+n \mathrm{H}_{2} \mathrm{O}
$$

The product distribution of FT synthesis follows the Anderson-Schultz-Flory model [Tock et al., 2010] as long as there is a constant probability of chain growth factor, $a$. The closer the value of $a$ to 1 the heavier are the produced hydrocarbons. The FT procedure results in olefins, alcohols, acids, oxygenates and paraffins of various chain length.

$\frac{W_{n}}{n}=(1-a)^{2} a^{(n-1)}$

$$
M_{n}=(1-a) a^{(n-1)}
$$

Where $W_{n}$ is the product mass fraction, $M_{n}$ is the product mole fraction and $n$ the number of carbon atoms. For enhancing mainly diesel and secondly gasoline production a value of $a$ equal to 0.9 is acceptable (Fig. 1). For simulation purposes, the produced hydrocarbons were classified, based on the carbon atoms, as follows [Wu et al., 2009]:

- $\quad \mathrm{C}_{1}-\mathrm{C}_{2} \rightarrow$ light gases

- $\mathrm{C}_{3}-\mathrm{C}_{4} \rightarrow$ liquefied petroleum gas (LPG)

- $\mathrm{C}_{5}-\mathrm{C}_{11} \rightarrow$ Gasoline

- $\mathrm{C}_{12}-\mathrm{C}_{20} \rightarrow$ Diesel

- $\mathrm{C}_{21}-\mathrm{C}_{30} \rightarrow$ Waxes 
The syngas after the cleaning and cooling treatment is compressed ( 25 bar) and heated up

used to simulate the FT reactor and the mass yields of the products exiting the reactor were

Spreadsheet where these calculations took place. Afterwards the product stream is cooled down and a flash drum is used in order to separate the hydrocarbons from the unconverted syngas which is recycled to the tar reformer. The hydrocarbon stream then enters the purification zone, after the water produced in the FT reactor is removed. In this section four distillation columns in total have been employed in order to recover the final products. The first has three outlet streams; the upper one for $\mathrm{C}_{2}-\mathrm{C}_{11} \mathrm{H} / \mathrm{C}$, the middle one for the diesel $\left(\mathrm{C}_{11}-\mathrm{C}_{20}\right)$ and the bottom one for the waxes $\left(\mathrm{C}_{21}-\mathrm{C}_{30}\right)$. The wax stream is subsequently pressurized and heated up to 50 bar and $618 \mathrm{~K}$ and enters the hydrocracking unit. The conversion efficiency of this unit was set equal to $88 \%$ while the required hydrogen $(0.65 \mathrm{wt}$ $\%$ of the wax feed) is produced throughout the process. The mass fractions of the hydrocracking unit are 80\% diesel, 15\% gasoline and 5\% light gases [Sudiro and Bertucco, 2009]. This stream is then sent to another distillation column which functions in the same way as the first one. The remaining waxes are recycled to the hydrocracking unit. The third distillation column separates light gases such as methane and ethane from the rest of the hydrocarbons $\left(\mathrm{C}_{3}-\mathrm{C}_{11}\right)$ and finally the last one separates LPG $\left(\mathrm{C}_{3}-\mathrm{C}_{4}\right)$ from gasoline $\left(\mathrm{C}_{5}-\mathrm{C}_{11}\right)$. to increase the octane number of the gasoline stream were not simulated but they were taken into consideration in the economic evaluation of the process. Finally the gas mixture 
comprising mainly carbon monoxide, hydrogen, methane and ethane enters a combined heat and power cycle (Brayton-Rankine) to generate electricity. Table 2 illustrates the FT product flowrates.

\subsection{The FP-H alternative}

During the past decade, several studies have reported techno-economic analyses of biomass fast pyrolysis to bio-oil, but very few have examined upgrading of bio-oil to transportation fuels [Peters et al., 2015]. In the present study, the Aspen plus model created for the FP-H option was divided into the following sections: 1) Pyrolysis unit, 2) Product quenching, 3) reforming) and compression and 5) Combined Heat and Power (Rankine cycle) unit.

The pyrolysis unit was simulated as a RYIELD reactor with a calculator block (including FORTRAN statements) that defines the product distribution of gas, tar and char according to Table 3 [Peters et al., 2015]. Two heat exchangers were used in order to cool the pyrolysis output stream and thereby condense the liquid products from the non-condensable gases. The cooling agent in the first exchanger is cooling water while in the second, ammonia was used as refrigerant. A portion of the gas stream $(30 \mathrm{wt} \%)$ is returned to the pyrolyser, acting as fluidising agent, while the remaining portion enters a CHP unit to generate electricity. The organic liquids need to be upgraded in order to give value added products. The upgrading process that was taken into consideration in this research was bio-oil hydrotreating and hydrocracking. These processes (also known as hydroprocessing) are typically utilised in the petroleum refinery sector in order to take away unwanted 
substances, including sulphur compounds, from crude oil and to crack down long chain hydrocarbon molecules, leaving as products clean gasoline and diesel. Bio-oil commonly consists of substantial amounts of oxygenated substances which are non-essential for internal combustion engine applications. During the hydrotreating procedure, oxygen contained in the bio-oil is incorporated into water and carbon dioxide, producing hydrocarbons which meet the requirements for combustion in vehicle engines. On the other hand, hydrocracking is a suitable technique to break down the structure of complex hydrocarbon compounds, contained in bio-oil, to gasoline-range and diesel-range product fractions.

Pyrolytic lignin (modelled as guaiacol [Jones et al., 2013]) is insoluble to water and can be separated from the other products and eventually enters a hydro-processing unit (hydrotreater and hydrocracker) in order to be upgraded to liquid fuels (gasoline, diesel, LPG). Hydrotreating takes place in a hydrogen-rich environment (approximately $95 \%$ mol), operating at 7 bar and $623 \mathrm{~K}$ and utilizes a cobalt-molybdenum catalyst. Hydrocracking operating conditions are 10 bar and 673K, employing a nickel-molybdenum catalyst. Two pumps and two heaters were employed to meet the required conditions of the hydrocracker and the hydrotreater. The final hydrocarbon distribution was assumed to be: Gasoline 30\%, simulated in the Aspen plus environment by employing two RYIELD reactors. Afterwards water is removed and two distillation columns separate the hydrocarbon fuels (diesel, gasoline and LPG). The first one separates LPG from the heavier hydrocarbon compounds and the second one gasoline from diesel. The light hydrocarbon products (LPG) are mixed 
with the non-condensable gas stream exiting the pyrolyser and sent to the CHP unit while diesel and gasoline products are safely stored. combustion reactions was set equal to $90 \%$. The flue gas is recovered by a common Rankine

\section{(Tab3 here)}

The rest of the organic liquids (water soluble phase) enter a pre-reformer unit, in order to produce syngas, where the water-gas-shift reactions occur. Subsequently, the stream enters, alongside methane (to enhance hydrogen productivity), a steam reformer reactor where hydrogen is generated according to the following catalytic reaction mechanism, using an iron based catalyst [Marquevich et al., 1999]:

$\mathrm{C}_{n} \mathrm{H}_{m} \mathrm{O}_{k}+(2 n-k) \mathrm{H}_{2} \mathrm{O} \rightarrow n \mathrm{CO}_{2}+\left(2 n+\frac{m}{2}-k\right) \mathrm{H}_{2}$

$\mathrm{CO}+\mathrm{H}_{2} \mathrm{O} \leftrightarrow \mathrm{CO}_{2}+\mathrm{H}_{2}$

Steam is supplied to the units from the quenching section. A conversion reactor module (RSTOICH) was utilised to model the reformer, setting the operating temperature at $700^{\circ} \mathrm{C}$. The conversion in the above reactions (Equation 6.23) was set equal to $80 \%$ and the unreacted organics are recycled into the reformer. A Pressure Swing Adsorption (PSA) unit (modelled as a common separator by setting the efficiency equal to $99 \%$ ) is used to separate hydrogen from carbon dioxide and then purified hydrogen is compressed to 70 bar through a multi-compressor. After the pyrolysis reactor the char is separated from the gaseous products in a cyclone and is led to a combustor where it is burnt with an excess (15\%) of preheated air. The combustor was simulated as a RSTOICH reactor where the conversion of the - steam cycle unit to generate power and heat. The electricity generated is enough to cover 

the power demands of the process and the excess can be sold as by-product to enhance the

272 profitability of the process. Table 2 depicts the basic process output data.

\section{Results - Discussion}

\subsection{Energy/Exergy efficiency}

275

277

284

285

286

287

288

289

In Sections 2.1 and 2.2, analysis of the energy inputs and outputs needed for the constituent processes within each option has been carried out the overall energy balance determined. The energy and exergy efficiencies ( $\eta$ and $\psi$ respectively) have been calculated; the aim of this section is to quantitatively compare these values and give a recommendation as to which option is most efficient. These thermochemical efficiencies, the most robust method of quantifying the efficiency of a process, compare the energy/exergy content of the desired fuel to the energy/exergy contained in the original feedstock in addition to all the chemical and net thermal energy inputs required throughout the conversion process as described in Eqs. (6-7). Fig. 2 comparatively illustrates the efficiencies.

$\eta=\frac{\dot{m}_{\text {fuel }} L H V_{\text {Fuels }}+Q_{\text {out }}+W_{\text {out }}}{\dot{m}_{\text {bagasse }} L H V_{\text {bagasse }}+Q_{\text {in }}+W_{\text {in }}}$

$\psi=\frac{E_{\text {Fuels }}+E_{\text {out }}^{Q}+W_{\text {out }}}{E_{\text {bagasse }}+E_{\text {in }}^{Q}+W_{\text {in }}}$

Where $\dot{m}_{f u e l}$ and $\dot{m}_{\text {bagasse }}$ are the mass flow rates of the produced fuels and bagasse, respectively and subscripts in and out stand for produced energy/exergy flows and external energy/exergy flows respectively. All the necessary thermodynamic data have been extracted from Aspen plus process simulator. Given the process technologies modelled and integrated, the G-FT conversion route of bagasse gives the higher energy/exergy ratios 
Exergy analysis has been finalised by calculating the cost related to the exergy destruction

of $68 \% / 62 \%$ and hence thermochemical energy efficiency. For FP-H the equivalent values are $58 \% / 56 \%$. This difference can be explained by the fact that the liquid fuels productivity is higher for the G-FT because the entire content of bagasse goes to fuels while in FP the lignin content is utilised in a CHP unit.

\section{(Fig. 2 here)}

\subsection{Irreversibilities}

Irreversibility $(I)$ counts for the total amount of exergy wasted in a process, or differently, the destroyed work potential. The lower the value of $I$, the higher the efficiency of a system. The following equation is used to calculate the irreversibility of the under investigation procedures [Lee et al., 2014]:

$\mathrm{I}=\sum \mathrm{E}_{\text {in }}-\sum \mathrm{E}_{\text {out }}+\mathrm{E}_{\text {in }}^{\mathrm{Q}}-\mathrm{E}_{\text {out }}^{\mathrm{Q}}+\mathrm{W}_{\text {in }}-\mathrm{W}_{\text {out }}$

Fig. 3 illustrates the exergy losses per section of each process. The wasted exergy in pyrolysis route is $150 \mathrm{MW}$ and more than half of it occurs in the pyrolysis reactor and the CHP unit. FT synthesis has lower exergy losses and the major contributor to them are the gasifier and the FT reactor.

(Fig. 3 here)

\subsection{Exergy costing}


can provide useful exergy equal to that lost under the same conditions. It can be described as

Where $I$ is the amount of exergy lost (irreversibly), $h$ is the annual working hours of the plant, $q$ the bagasse cost $(=20.5 £ / t$ [Furaln et al., 2013] or $1.16 £ / G J)$ and $\psi$ the exergetic efficiency. In order to precisely compare the outcomes derived from the irreversibility cost analysis, the total cost per exergy flow input $\left(C_{E}\right)$ was calculated as the ratio of the irreversibility cost $\left(C_{E}\right)$ over the exergy flow input of bagasse (see Table 4). It is quite obvious that there is a strong connection between efficiency and cost - the higher the efficiency the less the exergetic costs. As a result, the cost of producing G-FT fuels is higher than the FP-H fuels production cost.

\subsection{Financial analysis}

In this section, the economic sustainability of the proposed processes would be examined. The methodology is quite similar to the one proposed by Peters et al. [2003]. First of all the estimation of total capital investment (TCI) will be conducted and then the calculation of the annual operating costs (OC). Finally the estimation of net cash flows will be conducted. The cost of capital set equal to $7 \%$, straight line depreciation was selected (assets depreciated in 10 years), the currency is GBP (Great Britain Pounds), the annual operating hours are 8,000, the project lifetime is 20 years, the reference year is 2014 and the tax rate $40 \%$. Additionally any kind of subsidies related to the production of renewable value products has not been taken into account at this point. Various economic indicators, including net present value 
(NPV), IRR, ROI and payback period (PP), are estimated in order to assess each project's economic performance. Regarding to estimation of the total capital investment the first step is to calculate the equipment cost $(\mathrm{EC})$ of each process by employing the following equation:

Where $C$ is actual cost of the unit, $C_{0}$ is base cost of the unit, $S$ the actual size or capacity, $S_{0}$ the base size or capacity and $f$ the scale capacity factor. The values of the above variables have been adopted from the literature [Sadhukhan et al., 2014; Trippe et al., 2013; Sarkar and Kumar, 2010] while the value of the $S$ variable from the simulations. All the costs have been brought forward using the Chemical Engineering Plant Cost Index (CEPCI). Afterwards direct and indirect costs are calculated as a percentage of the equipment cost. The TCI is eventually the sum of EC, and direct and indirect costs. The operating cost comprises labour, catalyst and utilities cost and are illustrated in Table 5 [Vlysidis et al., 2011; Bridgwater et al., 2002; Bao et al., 2010; Caputo et al., 2005]. Finally, the selling price of the biofuels was adopted from a report published by the U.S.A. department of energy [2015] and these are 0.41/L for gasoline, 0.51/L for LPG, 0.54/L for Diesel and 1.92/kg for $\mathrm{H}_{2}$. Fig. 4 presents the economic performance of the processes. ACC stands for the annualised capital cost and it is calculated by utilizing Eq. (11). According to the economic analysis, the G-FT synthesis is slightly more profitable than the FP-H. The major bottleneck of the FP-H process is the cost (capital and operating) associated with the hydroprocessing unit. Consequently, the lower production cost of the G-FT fuels than the FP-H products, i.e. 11.5/GJ and 12.5/GJ respectively, is expectable.

355 Annualised Capital Cost $=T C I \times \frac{i \times(1+i)^{n}}{-1+(1+i)^{n}}$ 
(Fig. 4 here)

\subsection{Effect of the plant size}

360

In addition, the effect of the plant size on biofuels production cost was investigated. This was done by varying the input mass flow rate of bagasse. The results of this analysis are presented in Fig. 5. A second order decay trend can be observed for the production cost as the plant size increases. Beyond the baseline, the production cost slopes level out at a value of approximately $10 £ / G J$ for the G-FT fuels and $11 £ / G J$ for the FP-H fuels. The economies of scale favour the profitability of the processes, but one obstacle to this transition is the feedstock availability, since bagasse production is, of course, limited by the capacity of the plant from which it is a by-product. The equation utilised is the following [Lieberman, 1987]:

Production cost $=$ base cost $\times\left(\frac{\text { feedstock rate }}{\text { base feedstock rate }}\right)^{f}$

Where $f$ is the economic scale parameter and its suggested value for chemical processes is -0.33 [Peters et al, 2003].

(Fig. 5 here)

So far, it was presumed that the economic assessment was deterministic and the values of each key factor are well known with absolute certainty. However, in reality most, if not all, 
of these parameters are subject to changes. Therefore, in order to take into consideration these uncertainties the behaviour of NPV was examined with the values of total capital investment, revenues and operating cost varying from their calculated values within the bounds depicted in Table 6. Hence, a code was developed in Matlab environment based on Monte Carlo simulation principles which can calculate the NPV for random combinations of the above economic factors. The following histograms (Fig. 6) depict the results of this analysis and additionally the mean value and standard deviation for each case were estimated. The financial risk analysis indicates that G-FT process seems to be more reliable through the changes of key economic factors since its mean value of NPV is less than FP-H, i.e. $£ 20 \mathrm{M}$ and $£ 11 \mathrm{M}$ respectively as well as the standard deviation is lower, i.e. 77 and 122 .

\section{(Tab 6 here)}

\subsection{Sensitivity analysis}

Then, parametric analysis was carried out on the biofuels production cost by varying the technical parameters of each conversion option. It was observed that the most vital process variables for the FP-H procedure are the bio-oil yield (as a percentage of the total feed to the pyrolyser), catalyst cost of the hydroprocessing unit and the liquid fuel yield (as a percentage of the bio-oil). As for the G-FT pathway, the life time of the FT reactor catalyst, the per pass $\mathrm{CO}$ conversion in the FT reactor and the per pass wax conversion in the hydrocracker. The results of this analysis are shown in Fig. 7. It can be observed that at the 
400

401

402

403

404

405

406

407

408

409

410

411

412

413

414

415

416

417

418

419

420

421

most optimistic scenario the production cost of the FP-H products could be reduced to 12.1

$£ / G J$ which is still reasonably higher than the 11.2/GJ of the FT fuels.

\section{(Fig. 7 here)}

\section{Conclusions}

This study involved a comparative analysis of two near term biomass-to-liquid fuels conversion options. The feasibility of gasification followed by Fischer-Tropsch synthesis and fast pyrolysis coupled with hydroprocessing were investigated against thermodynamic and economic criteria. Sugar cane bagasse was chosen as feedstock at a flowrate of $100 \mathrm{t} / \mathrm{h}$. Robust and thermodynamically rigorous simulations of the constituent processes of these biofuel conversion options integrated were built in Aspen plus process simulation software. Based on the quantification and assessment of the yields, mass and energy balance of the constituent processes and overall thermochemical energy, and economic efficiencies were calculated for each option.

The higher fuels productivity associated with the G-FT process results in higher thermodynamic efficiencies than FP-H. During FP-H lignin is exploited in a steam cycle to generate electricity while in G-FT lignin is gasified and thereby it contributes to liquid fuels production. Moreover almost $40 \%$ of electricity generated from FP-H CHP unit is utilised to compress hydrogen. Pinch analysis, on the other hand, offers higher heat recovery potential for G-FT process which provides more opportunities for optimization (next step of the study). According to economic assessment G-FT outplays FP-H achieving higher values for all economic indicators. In addition it is more tolerant to fluctuations of the basic financial 

Botha, T., Von blottnitz, H., 2006. A comparison of the environmental benefits of bagasse-

specifications (TIC, OC and revenues). On the other hand the FP-H offers higher product diversity.

Taking into consideration the above mentioned remarks and results the choice of the best alternative conversion route depends on numerous aspects including factors aside from the calculated in this study, such as market demand and location of the plant. However at this point and solely based on thermo-economic criteria G-FT is more efficient than FP-H mainly due to higher thermodynamic performance, lower risk and considerable economic return.

\section{References}

Anex, R. P., Aden, A., Kazi, F. K., Fortman, J., Swanson, R. M., Wright, M. M., Satrio, J. A., Brown, R. C., Daugaard, D. E., Platon, A., Kothandaraman, G., Hsu, D. D., Dutta, A., 2010. Techno-economic comparison of biomass-to-transportation fuels via pyrolysis, gasification, and biochemical pathways, Fuel. 89 Supplement 1, S29-S35.

Bao, B., El-Halwagi, M. M., Elbashir, N. O., 2010. Simulation, integration, and economic analysis of gas-to-liquid processes, Fuel Processing Technology. 91, 703-713.

Boerrigter, H., 2006. Economy of Biomass-to-Liquids (BTL) plants - An engineering assessment. Report ECN-C--06-019, Energy research Centre of the Netherlands. derived electricity and fuel ethanol on a life-cycle basis, Energy Policy. 34, 2654-2661. 
Bridgwater, A. V., Toft, A. J., Brammer, J. G., 2002. A techno-economic comparison of power production by biomass fast pyrolysis with gasification and combustion, Renewable and Sustainable Energy Reviews. 6, 181-246.

Caputo, A. C., Palumbo, M., Pelagagge, P. M., Scacchia, F., 2005. Economics of biomass energy utilization in combustion and gasification plants: effects of logistic variables, Biomass and Bioenergy. 28, 35-51.

Cardona, C. A., Quintero, J. A., Paz, I. C., 2010. Production of bioethanol from sugarcane bagasse: Status and perspectives, Bioresource Technology. 101, 4754-4766.

Chandel, A. K., Da Silva, S. S., Carvalho, W., Singh, O. V., 2012. Sugarcane bagasse and leaves: foreseeable biomass of biofuel and bio-products, Journal of Chemical Technology \& Biotechnology. 87, 11-20.

Chauhan, M. K., Varun, Chaudhary, S., Kumar, S., Samar, 2011. Life cycle assessment of sugar industry: A review, Renewable and Sustainable Energy Reviews. 15, 3445-3453. C., 2013. Bioelectricity versus bioethanol from sugarcane bagasse: is it worth being flexible? Biotechnology for Biofuels, 6, 142. methods on chemical composition of sugarcane bagasse and enzymatic hydrolysis, Bioresource Technology. 144, 396-400. transportation fuels from biomass; technical options, process analysis and optimisation, and development potential. Energy, 29, 1743-1771.

Jones, S., Meyer, P., Snowden-Swan, L., Padmaperuma, A., Tan, E., Dutta A., Jacobson, J., Cafferty, K., 2013. Process Design and Economics for the Conversion of Lignocellulosic Biomass to Hydrocarbon Fuels - Fast Pyrolysis and Hydrotreating Bio-oil Pathway. Report PNNL-23053, Pacific Northwest National Laboratory. 
Kemp, I. C., 2007. Pinch analysis and process integration: a user guide on process integration for the efficient use of energy, Amsterdam; Boston, Butterworth-Heinemann.

Kiatkittipong, W., Wongsuchoto, P., Pavasant, P., 2009. Life cycle assessment of bagasse waste management options, Waste Management. 29, 1628-1633.

Lee, J. C., Lee, H. H., Joo, Y. J., Lee, C. H., Oh, M., 2014. Process simulation and thermodynamic analysis of an IGCC (integrated gasification combined cycle) plant with an entrained coal gasifier, Energy. 64, 58-68.

Lieberman M. B. 1987. Market Growth, Economies of Scale, and Capacity Expansion in the Chemical Processing Industries. Journal of Industrial Economics. 36, 175-191.

Luo, L., Van Der Voet, E., Huppes, G., 2009. Life cycle assessment and life cycle costing of bioethanol from sugarcane in Brazil, Renewable and Sustainable Energy Reviews. 13, 16131619.

Luo, S., Liu, C., Xiao, B., Xiao, L., 2011. A novel biomass pulverization technology, Renewable Energy. 36, 578-582.

Marquevich, M., Czernik, S., Chornet, E., Montané, D., 1999. Hydrogen from Biomass: Steam Reforming of Model Compounds of Fast-Pyrolysis Oil, Energy \& Fuels. 13, 1160-1166.

Martín, C., Villamañán, M. A., Chamorro, C. R., Otero, J., Cabanillas, A. \& Segovia, J. J. 2006. Low-grade coal and biomass co-combustion on fluidized bed: exergy analysis. Energy, 31, 330-344.

Murphy, C. W, Kendall, A., 2015. Life cycle analysis of biochemical cellulosic ethanol under multiple scenarios, GCB Bioenergy. 7, 1019-1033.

Ng, K. S., Sadhukhan, J., 2011. Techno-economic performance analysis of bio-oil based Fischer-Tropsch and CHP synthesis platform. Biomass and Bioenergy. 35, 3218-3234.

Peters, J. F., Iribarren, D., Dufour, J., 2015. Simulation and life cycle assessment of biofuel production via fast pyrolysis and hydroupgrading, Fuel. 139, 441-456. 
Peters, M. S., Timmerhaus, K. D, West, R. E., 2003. Plant design and economics for chemical engineers, New York, McGraw-Hill.

Sadhukhan, J., Ng, K. S., Hernandez, E. M., 2014. Economic Analysis. Biorefineries and Chemical Processes, John Wiley \& Sons, Ltd.

Sarkar, S., Kumar, A., 2010. Large-scale biohydrogen production from bio-oil, Bioresource Technology. 101, 7350-7361.

Sudiro, M., Bertucco, A., 2009. Production of synthetic gasoline and diesel fuel by alternative processes using natural gas and coal: Process simulation and optimization, Energy. 34, 22062214.

Swanson, R.M., Satrio, J.A., Brown R.C., Platon, A., Hsu D.D., 2010. Techno-Economic Analysis of Biofuels Production Based on Gasification. Report NREL/TP-6A20-46587, National Renewable energy Laboratory.

Tock, L., Gassner, M., Maréchal, F., 2010. Thermochemical production of liquid fuels from biomass: Thermo-economic modeling, process design and process integration analysis, Biomass and Bioenergy. 34, 1838-1854.

Trippe, F., Fröhling, M., Schultmann, F., Stahl, R., Henrich, E., Dalai, A., 2013. Comprehensive techno-economic assessment of dimethyl ether (DME) synthesis and Fischer-Tropsch synthesis as alternative process steps within biomass-to-liquid production, Fuel Processing Technology. 106, 577-586.

Vlysidis, A., Binns, M., Webb, C., Theodoropoulos, C., 2011. A techno-economic analysis of biodiesel biorefineries: Assessment of integrated designs for the co-production of fuels and chemicals, Energy. 36, 4671-4683.

Wright, M.M., Satrio, J.A., Brown R.C., Daugaard, D.E., Hsu D.D., 2010. Techno-Economic Analysis of Biomass Fast Pyrolysis to Transportation Fuels. Report NREL/TP-6A20-46586, National Renewable energy Laboratory.

Wright, M. M., Daugaard, D. E., Satrio, J. A. \& Brown, R. C., 2011. Techno-economic analysis of biomass fast pyrolysis to transportation fuels, Fuel. 89 Supplement 1, S2-S10. 
$522 \mathrm{Wu}$, X., McLaren, J., Madl, R., Wang, D., 2009. Biofuels from Lignocellulosic Biomass. In:

523 Singh, V.O., Harvey, P.S., (eds.) Sustainable Biotechnology: Sources of Renewable Energy.

524 Dordrecht: Springer Netherlands.

525 Zhu, Y., Tjokro, Rahardjo S.A, Valkenburg, C., Snowden-Swan, L.J., Jones, A.B., Machinal, 526 M.A., 2011. Techno-economic Analysis for the Thermochemical Conversion of Biomass to 527 Liquid Fuels. Report PNNL-19009, Pacific Northwest National Laboratory.

528

529 Nomenclature

530 Abbreviations

531 EC Basic equipment cost

532 FP $\quad$ Fast pyrolysis

533 FT Fischer-Tropsch

534 HHV Higher heating value

535 IRR Internal rate of return

536 LHV Lower heating value

537 NPV Net present value

538 OC Operating cost

539 PP Payback period

540 ROI Return on investment

541 TCI Total capital investment

$542 \quad$ Variables

543 C Cost

$544 \quad \mathrm{C}_{0} \quad$ base cost of a unit

545 E exergy content [MW]

546 EQ exergy content of a heat stream [MW]

$547 \quad \varepsilon_{c h} \quad$ chemical exergy $[\mathrm{MJ} / \mathrm{kg}]$

$548 \quad \varepsilon_{\mathrm{ph}} \quad$ physical exergy $[\mathrm{MJ} / \mathrm{kg}]$

$549 \mathrm{f} \quad$ scale capacity factor

$550 \quad \dot{m}_{\text {bagasse }} \quad$ mass flow of bagasse $[\mathrm{kg} / \mathrm{s}]$

$551 \dot{m}_{\text {fuel }} \quad$ mass flow rates of the produced fuels $[\mathrm{kg} / \mathrm{s}]$ 
552 S actual size or capacity of a unit,

$553 \quad$ S0 base size or capacity of a unit

$554 \quad$ W $\quad$ Work $[\mathrm{MW}]$

555 Greek Letters

$556 \alpha \quad$ chain growth probability

$557 \quad \eta \quad$ energy efficiency

$558 \quad \psi \quad$ exergy efficiency

559

560 Fig. 1 - Fischer-Tropsch product distribution for $a=0.9$

561 Fig. 2 - Thermodynamic efficiencies of G-FT and FP-H processes for sugar cane bagasse as

562 simulated in this study

563 Fig. 3 - Exergy losses per section of each conversion route $(a \rightarrow$ G-FT, $b \rightarrow$ FP-H)

564 Fig. 4- Financial data for the G-FT and FP-H processes

565 Fig. 5 - Effect of plant size on production cost

566 Fig. 6 - Risk analysis of NPV for the investigated processes $(a \rightarrow$ G-FT, $b \rightarrow$ FP-H $)$

567 Fig. 7 - Sensitivity analysis on biofuels production cost for each alternative 


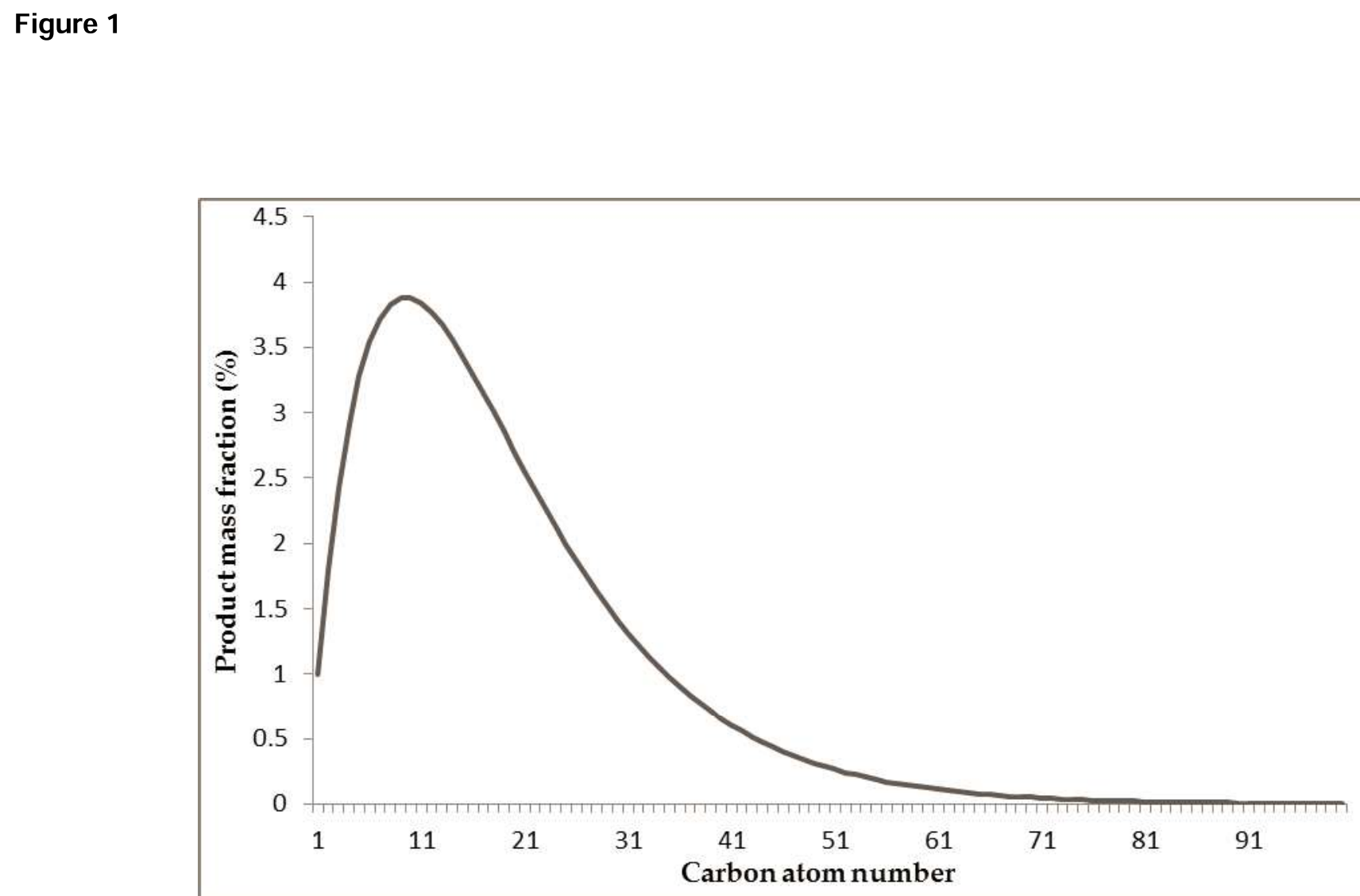
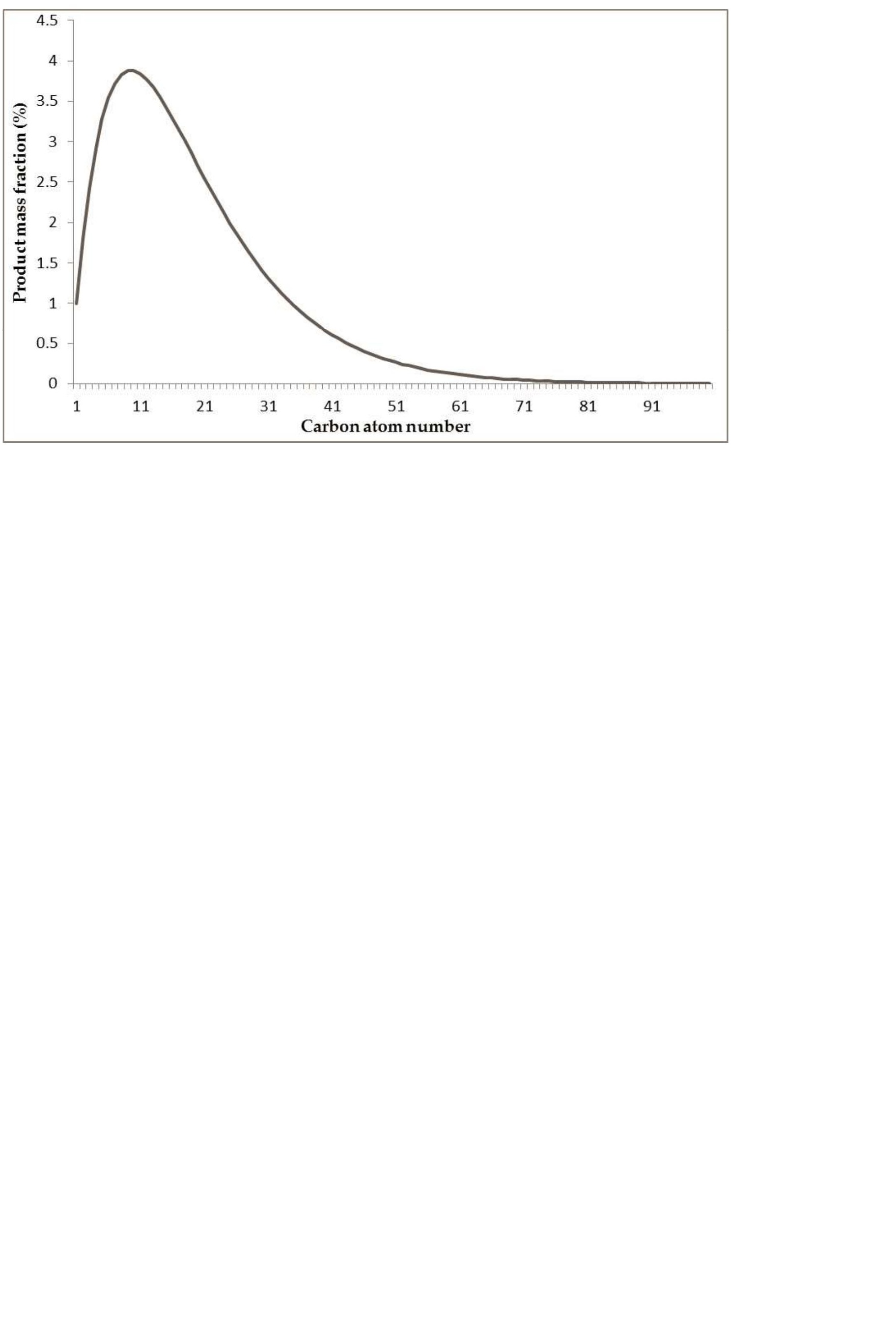
Figure 3
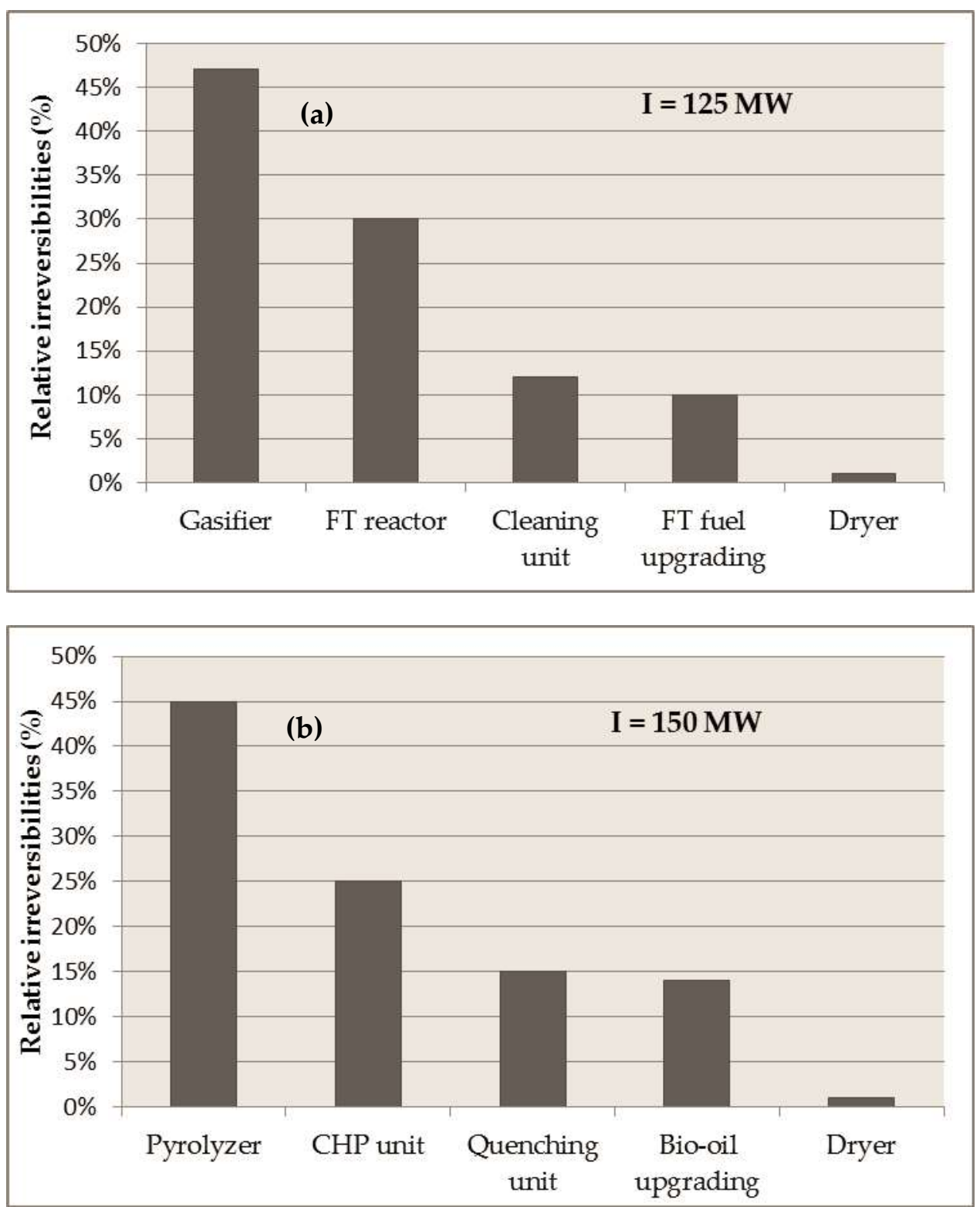
Figure 4
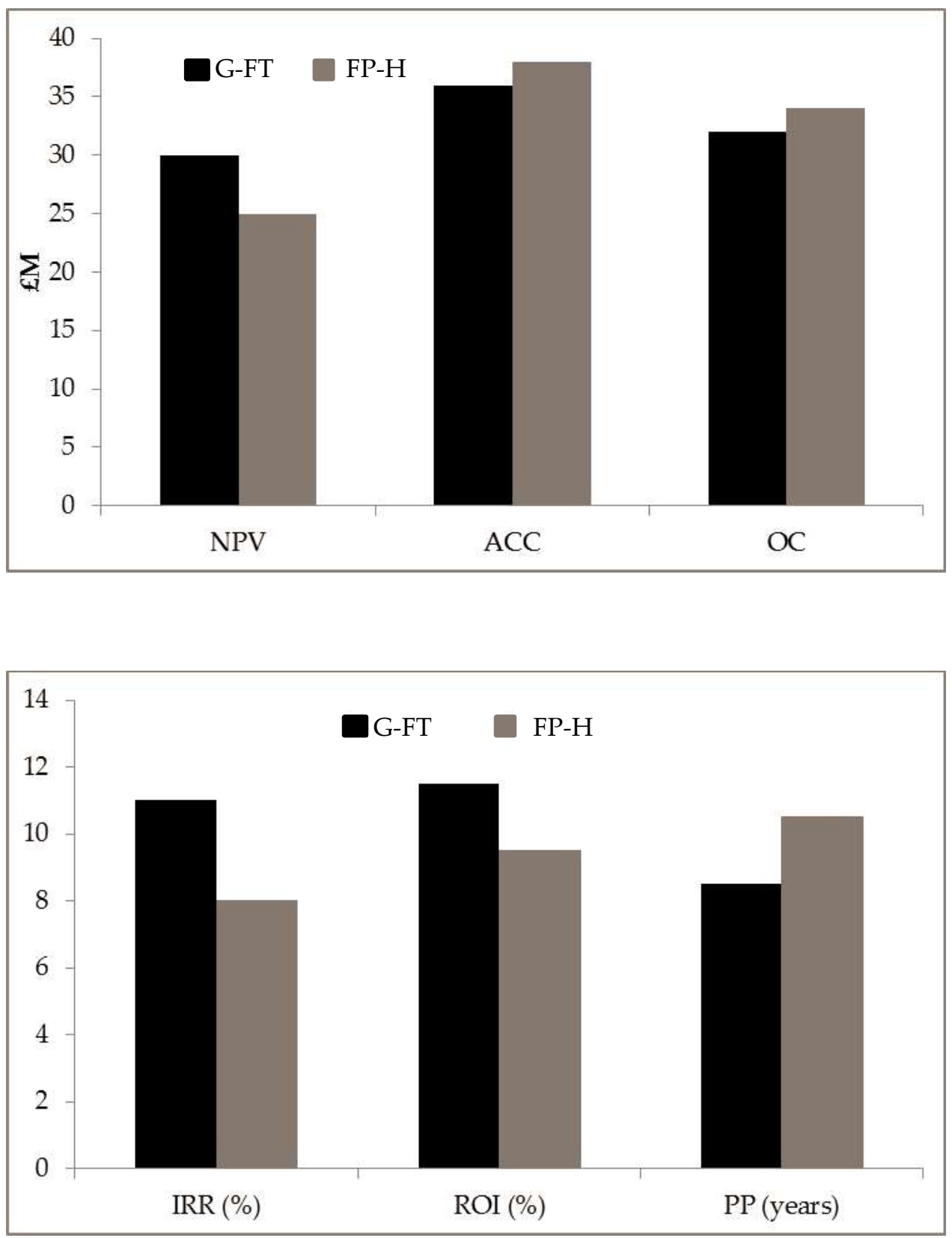
Figure 6
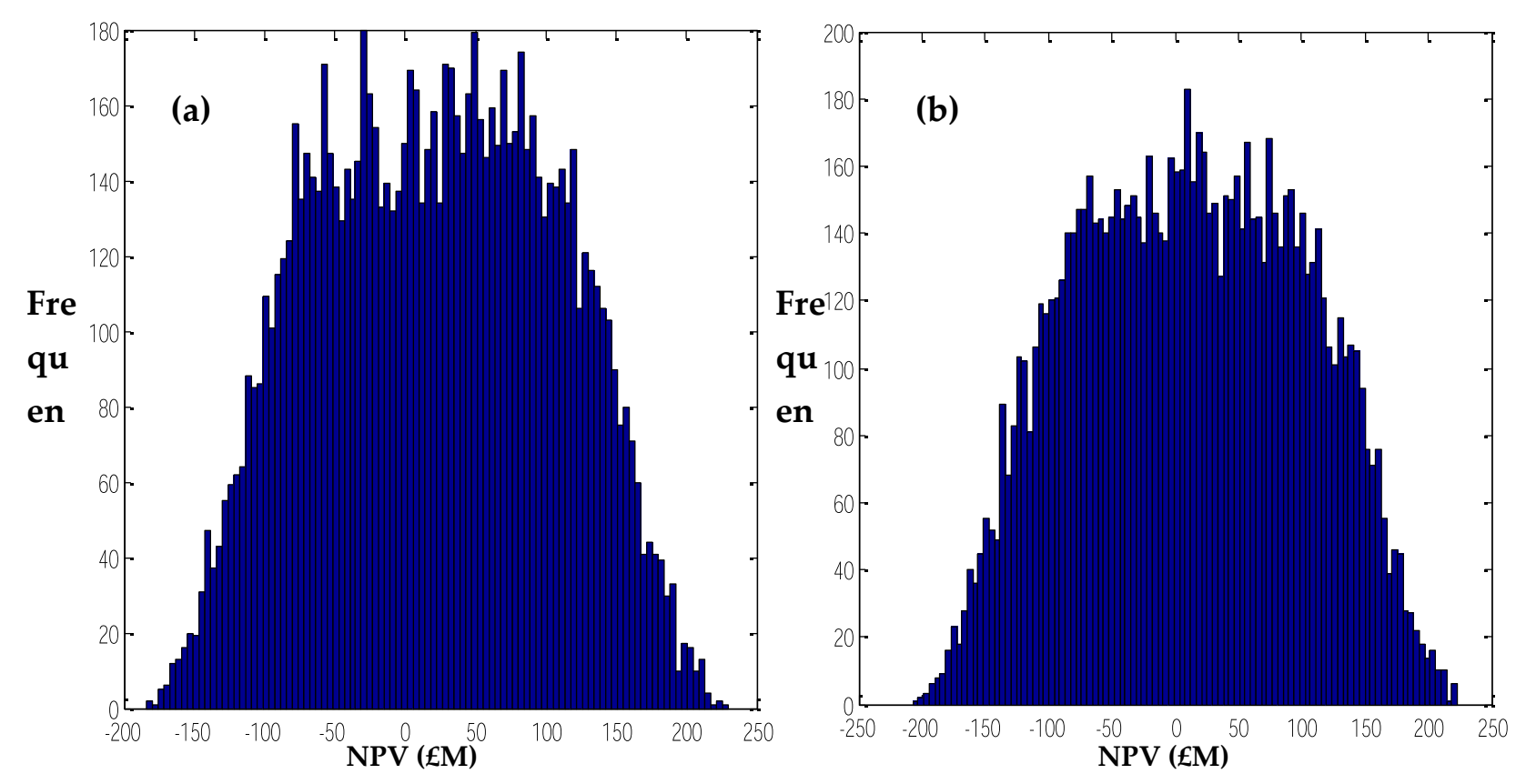


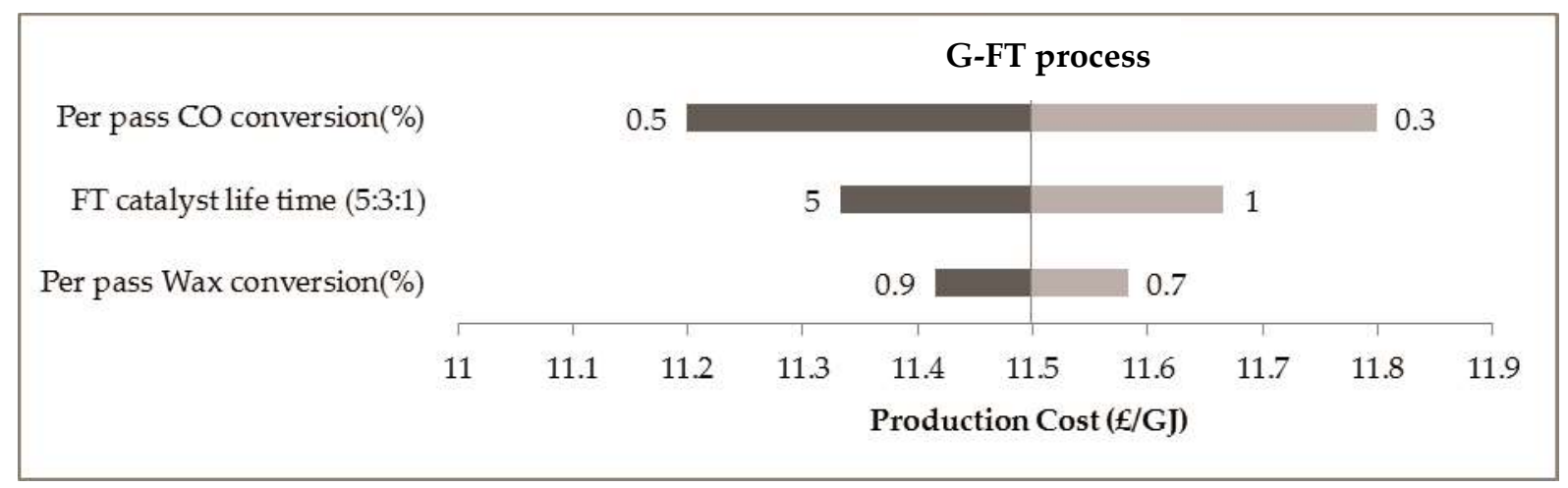

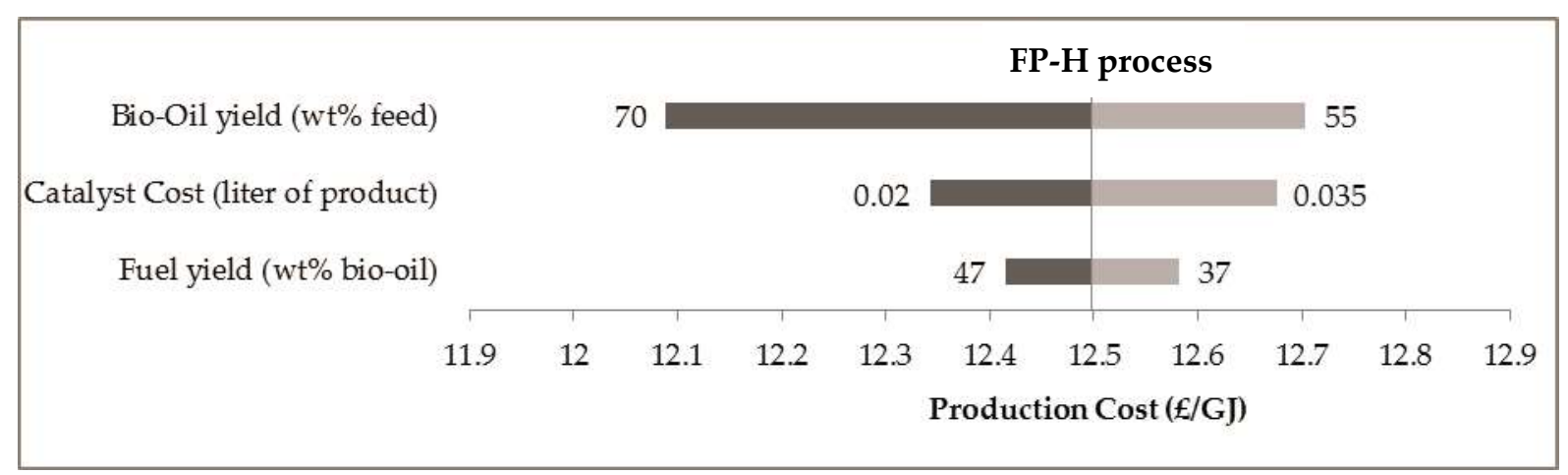


Table 1 - Typical bagasse Proximate and Ultimate analysis [Cao et al., 2013]

\section{Proximate analysis}

\begin{tabular}{lc}
\hline Parameters & Composition (wt \%) \\
\hline Moisture & $50(\mathrm{w} . \mathrm{b})$ \\
Ash & $3.2(\mathrm{~d} . \mathrm{b})$ \\
Volatile matter (dry Basis) & $83.65(\mathrm{~d} . \mathrm{b})$ \\
Fixed Carbon (dry basis) & $13.15(\mathrm{~d} . \mathrm{b})$ \\
\hline \multicolumn{2}{c}{ Ultimate analysis } \\
\hline Element & Dry Weight (\%) \\
\hline $\mathrm{C}$ & 45.38 \\
$\mathrm{H}$ & 5.96 \\
$\mathrm{O}$ & 45.21 \\
$\mathrm{~N}$ & 0.15 \\
$\mathrm{~S}$ & 0.1 \\
\hline
\end{tabular}


Table 2 - Products of the G-FT and FP-H systems used in this study

$$
\text { G-FT FP-H }
$$

Diesel productivity $(\mathrm{kg} / \mathrm{h})$

9100

1,200

Gasoline productivity $(\mathrm{kg} / \mathrm{h})$

6050

4,500

LPG productivity $(\mathrm{kg} / \mathrm{h})$

1175

2,250

Hydrogen productivity $(\mathrm{kg} / \mathrm{h})$

$\begin{array}{ll}- & 3,700\end{array}$

Electricity surplus (MW)

6.5

15 
Table 3 - Typical biomass pyrolysis product distribution [Peters et al., 2015]

\begin{tabular}{lc}
\hline Product & wt.\% \\
\hline $\mathrm{CO}$ & 2.20 \\
$\mathrm{CO}_{2}$ & 6.30 \\
$\mathrm{CH}_{4}$ & 0.40 \\
$\mathrm{H}_{2}$ & 0.20 \\
$\mathrm{C}_{2} \mathrm{H}_{6}$ & 0.40 \\
Water & 9.52 \\
Glyoxal & 4.26 \\
Acetol & 2.04 \\
Hydroxyacetaldehyde & 7.24 \\
Acetic acid & 7.24 \\
Formic acid & 5.45 \\
Ethylene Glycol & 0.86 \\
Sugars (modelled as glucose) & 15 \\
Pyrolytic lignin (modelled as guaiacol) & 17.6 \\
Solid carbon & 18.08 \\
Ash & 3.20 \\
\hline
\end{tabular}


Table 4 - Annual costs of irreversibilities for the examined processes

\begin{tabular}{lcccc}
\hline Process & $\boldsymbol{\psi}(\mathbf{\%})$ & $\mathrm{C}_{\mathrm{E}}(\mathbf{M} £)$ & Exergy input $(\mathbf{M W})$ & $\mathbf{c}_{\mathrm{E}}(£ / \mathbf{M W})$ \\
\hline G-FT & 62 & 1.87 & 280 & 6,700 \\
FP-H & 56 & 2.5 & 280 & 8,930 \\
\hline
\end{tabular}


Table 5 - General operating costs (OC) for processing bagasse

\begin{tabular}{|c|c|}
\hline Utility and Chemicals & Cost $(E)$ \\
\hline Feedstock price & $10 / \mathrm{t}$ \\
\hline Labour & 30,000/labour \\
\hline Feed boiler water & $0.15 / \mathrm{m}^{3}$ \\
\hline Electricity & $0.07 / \mathrm{kWh}$ \\
\hline Process steam & $0.018 / \mathrm{kWh}$ \\
\hline Cooling Water & $0.0007 / \mathrm{kWh}$ \\
\hline FT catalyst & $16 / \mathrm{kg}$ \\
\hline Pyrolysis catalyst & $24.47 / \mathrm{kg}$ \\
\hline Tar reformer catalyst & $21 / \mathrm{kg}$ \\
\hline Wax hydrocracker catalyst & $18 / \mathrm{kg}$ \\
\hline Pyrolysis hydroprocessing catalyst & $0.027 / \mathrm{L}$ of produced liquid fuels \\
\hline Methane & 1.43/GJ \\
\hline
\end{tabular}


Table 6 - Limits used for key financial variables

\begin{tabular}{cc}
\hline Profitability factor & Variation (\%) \\
\hline TCI & -10 to 25 \\
OC & -15 to 25 \\
Revenues & -30 to 25 \\
Interest rate & -25 to 25 \\
\hline
\end{tabular}

